\title{
A case-control study of pattern and determinants of quality of life of patients with diabetes in a developing country
}

\author{
Ofem Enang ${ }^{1}$, Ogban Omoronyia $2^{*}$ (D), Udeme Asibong ${ }^{3}$, Agam Ayuk $^{3}$, Kenneth Nwafor $^{3}$ and Annette Legogie ${ }^{3}$
}

\begin{abstract}
Background: Globally, diabetes is a leading cause of impairment of quality of life. In the sub-Saharan African region, there is a need for studies that provide more valid assessment of effect of diabetes on quality of life (QoL). This study aimed at assessing quality of life among patients with diabetes attending a tertiary health service in Nigeria.

Methods: The study design was a case-control. Diabetic cases were randomly recruited from the University of Calabar Teaching Hospital, while non-diabetic controls were civil servants and retirees. The validated and pretested WHOQoL-BREF instrument was used to assess quality of life, with higher scores indicating higher quality of life.

Results: Three hundred and thirty subjects were studied, with mean ages of males and females of $55.2 \pm 4.8$ and $51.8 \pm 6.3$ years, respectively. The mean total QoL score was $75.77 \pm 11.2$, with no significant difference between males and females. Among male and female cases, the mean score of the physical health domain was significantly lower for cases compared with controls $(p=0.05)$. Male cases compared with controls had higher scores for the environment domain $(p<0.05)$. Older age and higher systemic blood pressure were associated with lower QoL scores for both sexes $(p<0.05)$. Unmarried status, obesity, and poor glycemic control $(\mathrm{HbA} 1 \mathrm{c}>7 \%)$ were associated with lower QoL scores $(p<0.05)$. Fasting blood sugar (FBS) level and lipid profile were not significantly correlated with QoL score in both sexes $(p>0.05)$.

Conclusion: Diabetes contributes to low quality of life among males and females, with significant differences in the affected domains. Diabetes care providers should identify affected domains during clinic consultation, in order to improve provision of more effective care.
\end{abstract}

Keywords: Diabetes mellitus, Quality of life, Calabar, Nigeria

\section{Background}

National and global health systems are ultimately aimed at preventing disease and promoting health, especially via goal-oriented improvement in longevity and quality of life $[1,2]$. Chronic non-communicable diseases (NCDs) constitute a potential rate-limiting step towards attainment of the current sustainable development goals (SDGs), since their presence and degree of control is

\footnotetext{
*Correspondence: omoronyia2016@gmail.com

${ }^{2}$ Department of Community Medicine, University of Calabar, Calabar, Nigeria Full list of author information is available at the end of the article
}

one of the greatest determinants of health-related quality of life [3].

Health-related quality of life (HRQoL), which refers to sociocultural and time-specific sense of well-being, is assessed in different areas of life, mainly comprising physical, psychological, social, and environment domains that are related to health [4]. The onset, progression, and prognosis of most chronic diseases are key determinants of HRQoL. Diabetes mellitus is one of such NCDs, which has continued to make significant contribution to high burden of disease and adverse impact on HRQoL in both developed and developing countries $[5,6]$. An

\section{Springer Open}

(c) The Author(s). 2021 Open Access This article is licensed under a Creative Commons Attribution 4.0 International License, which permits use, sharing, adaptation, distribution and reproduction in any medium or format, as long as you give appropriate credit to the original author(s) and the source, provide a link to the Creative Commons licence, and indicate if changes were made. The images or other third party material in this article are included in the article's Creative Commons licence, unless indicated otherwise in a credit line to the material. If material is not included in the article's Creative Commons licence and your intended use is not permitted by statutory regulation or exceeds the permitted use, you will need to obtain permission directly from the copyright holder. To view a copy of this licence, visit http://creativecommons.org/licenses/by/4.0/. 
estimated 451 million people are diabetic, and 693 million are projected to have the chronic disease by 2045 [7]. This suggests that in the coming years and decades, HRQoL is expected to consistently decrease due to rising burden of diabetes and other NCDs.

Decreased HRQoL affects virtually all facets of human existence, including national and domestic productivity [4]. Developing countries which need to do much more productively to grow their economies may therefore be worse hit by impaired HRQoL effects of chronic diseases [6]. Best practice of diabetes care aims at attaining nearnormal control of blood sugar without significantly affecting HRQoL of patients [8]. Studies in developing countries have shown high prevalence of poor glycemic control among patients with diabetes, potentially contributing to impairment in their HRQoL [9]. Also, a multi-center study among diabetic patients in Nigeria found $67.6 \%$ prevalence of poor glycemic control [10]. Still, attainment of good glycemic control demands lifelong self-monitoring and care and awareness of risk of occurrence and progression of complications [9]. This potential impairment in quality of life may in turn lead to poor compliance with treatment, disease progression, and eventual poor prognostic outcome $[6,11]$.

Yet, in sub-Saharan Africa (SSA) where the disease is on the rapid rise with poor healthcare access, most studies of HRQoL among type 2 diabetics are descriptive cross-sectional studies, without at least comparison or control group(s), which provide more credible evidence of disease impact on QoL [12-16]. HRQoL may be affected by several other factors including poverty, insecurity, unemployment, and chronic diseases, which are also prevalent in the region. Therefore, there is a need for better understanding of level and determinants of HRQoL among patients with diabetes in the region. This will enable better improvement in quality of diabetic care services provided in developing countries [6]. The purpose of this study was to assess the pattern and determinants of HRQoL among patients with diabetes in Nigeria using a control group of healthy non-diabetics.

\section{Methods}

\subsection{Study design and participants}

This case-control study explored HRQoL among adults with type 2 diabetes in Calabar, Southern Nigeria. Primary data for cases was obtained from diabetic patients seen in medical wards and outpatient clinics in the University of Calabar Teaching Hospital (UCTH), while age/ sex-matched controls were non-diabetic and normotensive civil servants and retirees. The teaching hospital is a referral center for diabetes care in the region and runs a weekly diabetes clinic. Five (5) civil service ministries were randomly selected from the existing twelve (12) ministries in Calabar to recruit the controls.

\subsection{Sampling}

Sample size $n$ was calculated using the formula: $n=\left\{Z_{1}\right.$ $-\alpha / 2 \sqrt{ }\left(2 P(1-P)+Z_{1}-\beta \sqrt{ }\left[P^{*}\left(1-P^{*}\right)+P(1-P)\right]\right\}^{2} / D^{2}$ [17] where $Z_{1}-\alpha / 2$ is the critical value at $5 \%$ level of significance $=1.96, Z_{1}-\beta$ is the standard normal deviate corresponding to $80 \%$ power $=0.84, P$ is the proportion of general population with poor quality of life (0.184), reported in previous study in Nigeria [18], $P^{*}$ is the estimated proportion of diabetics with poor quality of life assuming odds ratio of 2 as important difference between the two groups $=0.33$, and $D$ is the effect size $\left(P^{*}-P\right)$. With assumption of $5 \%$ non-response rate, a sample size of 165 was obtained for each of the two arms, yielding a total sample size $N$ of three hundred and thirty $(n=330)$ subjects. Systematic random sampling was used to recruit cases and controls, using the registers of the medical outpatient clinic and departmental civil service as the sampling frames, respectively.

\subsection{Data collection}

The English version of WHOQoL-BREF instrument [19] was used in this study. It is a 26-item questionnaire comprising physical health, psychological health, social relationships, and environment domains. Two items assess overall quality of life and general health, while 7, 6, 3 , and 8 items assess physical health, psychological health, social relationship, and environmental health, respectively. Each item has a 5-point Likert scale, and the mean score of items in each domain contributes to the domain score which is multiplied by four (4) to correspond to a 0 to 100 scale. Negatively phrased questions comprising items 3,4 , and 26 were reversely scored $(5=$ $1,4=2,3=3,2=4,1=5)$. Greater score indicates better quality of life and vice-versa [20]. The instrument has been validated in diverse global settings including Nigeria [21] and was pretested in this study, with yield of Cronbach's alpha of 0.79 before use for data collection. Trained research assistants administered the questionnaire in English. Fasting blood sugar, HbA1c, triglyceride, cholesterol, HDL-c, and LDL-c were assessed using venous blood samples drawn following overnight fast by subjects. Auto analyzer (Hitachi 902) was used by trained laboratory scientist to measure these parameters, in tune with the manufacturer's guidelines. Height (to the nearest $0.5 \mathrm{~cm}$ ) and weight (to the nearest $0.1 \mathrm{~kg}$ ) were assessed using standard calibrated stadiometer (SECA, Hamburg, Germany), with subjects having light clothing and not wearing any shoes. BMI $\left(\mathrm{kg} / \mathrm{m}^{2}\right)$ was calculated as ratio of weight (in $\mathrm{kg}$ ) and square of height (in meters). After at least 5 min of rest, systemic blood pressure was measured by a trained nurse using 
desk-type analog mercury sphygmomanometer (Accoson, Dekamet, UK), with subject sitting upright and legs uncrossed. Measurement was repeated after $30 \mathrm{~min}$, and the mean value was reported for both systolic and diastolic blood pressures.

\subsection{Statistical analysis}

Data entry and analysis was done using SPSS version 21.0. Subject characteristics were described using measures of central tendency, dispersion, and frequency. State of glycemic control among cases was determined using HbA1c level, with subjects having $7.0 \%$ or higher were considered to have poor control and vice-versa [22]. Frequency cross-table was used to present comparison of sociodemographic, anthropometric, and clinical characteristics between cases and controls, with Chi-square or Fisher's exact as inferential test for differences between proportions. Independent $t$ test was used to compare mean values of each of the items and domains of QoL between cases and controls. Comparison of mean values of each of the domains of QoL was done for sociodemographic and clinical characteristics using independent $t$ test and analysis of variance (ANOVA) for characteristics with two or more categories, respectively. Pearson correlation analysis was done to assess the relationship between continuous biochemical variables and QoL scores. The $p$ value was set at 0.05 .

\section{Results}

Complete data from three hundred and thirty subjects comprising eighty-seven (87) male and seventy-eight (78) female diabetic cases and equal number of age/sexmatched controls yielded a response rate of $95.4 \%$. The mean ages of males and females were $55.2 \pm 4.8$ and $51.8 \pm 6.3$ years, respectively. Most subjects were within the range of $51-70$ years $(66.0 \%)$, were married $(80.9 \%)$, had at least secondary level of education (88.8\%), and never smoked (72.4\%) (Table 1). The commonest religion was Roman Catholic (41.2\%). Being widowed, having lower level of education, previous smoking history, and consuming alcohol occasionally were significantly more common among cases compared with controls $(p<0.01$, Table 2). The mean BMI was $26.7 \pm 4.7$, and most subjects (61.2\%) were either overweight or obese, with significantly higher proportion among cases compared with controls $(p<0.01)$. Hypertension was found in $85.5 \%$ of cases, with mean duration of hypertension being $8.5 \pm 3.6$ years, ranging from 1 to 15 years. Also, among cases, the mean HbA1c was $8.46 \pm 2.2 \%$ (4.40-13.60), and $29.1 \%$ had good control. There was no significant difference in level of control comparing males and females ( 8.61 vs. $8.30 \%, p=0.37$ ). Comparing cases with good and poor control of diabetes, there was no significant difference in mean scores of total (76.8 vs. 73.4), psychological (19.6 vs. 19.0), social relationship (9.46 vs. 9.38), and environment (24.6 vs. 23.6$)$ domains of quality of life $(p>0.05)$. However, physical quality of life was significantly lower among cases with poor compared with good control of their diabetes (21.4 vs. 23.2, $p=0.03)$.

The mean QoL score for all (male and female) patients with diabetes was $75.77 \pm 11.2$, with no significant difference between males and females $(77.1 \pm 10.6$ vs. $76.3 \pm$ 10.4, $p>0.05)$. Among females, the mean score of the physical health domain was significantly lower for cases compared with controls $(p<0.01$, Table 2$)$. The mean scores for psychological health, social relationship, and environment domains were not significantly different between cases and controls $(p>0.05)$. However, the mean scores for one of the three items in social relationship and four of the eight items in environment domains were significantly lower among cases compared with controls $(p<0.05)$.

Table 3 compared the mean scores of each item and domain of QoL among male cases and controls. Physical health and social relationship domains had significantly lower mean sum scores for cases compared with controls $(p<0.05)$. Four of seven, one of six, one of three, and two of eight items were significantly lower among cases compared with controls for physical, psychological health, social relationship, and environment domains, respectively $(p<0.05)$. Psychological health and environment domains had mean sum scores that were higher among cases compared with controls, but statistical significance was found only for the environment domain $(p$ $<0.05)$.

Table 4 assesses the relationship between sociodemographic characteristics and QoL among cases. Among females, the mean score of the physical health domain was significantly lower among those older than 50 years $(p<$ 0.05). Also, the mean score of social relationship was significantly lower for cases who were unmarried and those who never consumed alcohol $(p<0.05)$. The level of education and religion were not significantly associated with the mean scores of all the domains $(p>0.05)$. Among males, older cases had lower QoL scores for all domains, but statistical significance was found only for the environment domain $(p<0.05)$. Marital status, level of education, religion, and satisfaction about sexual life were not significantly associated with the mean QoL scores for all the domains $(p>0.05$, Table 3$)$.

Table 5 shows the relationship between clinical, laboratory parameters, and QoL scores among male and female cases. In both sexes, QoL score was significantly lower among those who had abnormal BMI (overweight or obese) and poor glycemic control $(\mathrm{HbA} 1 \mathrm{C} \geq 7.0 \%)(p<0.05)$. Lower $\mathrm{QoL}$ was also 
Table 1 Characteristics of patients with diabetes and controls in Calabar, Nigeria $(N=330)$

\begin{tabular}{|c|c|c|c|c|}
\hline Characteristic & $\begin{array}{l}\text { Case }(n=165) \\
n(\%)\end{array}$ & $\begin{array}{l}\text { Control }(n=165) \\
n(\%)\end{array}$ & $\begin{array}{l}\text { Total }(n=330) \\
n(\%)\end{array}$ & $\begin{array}{l}\text { Chi-square } \\
\text { ( } p \text { value) }\end{array}$ \\
\hline \multicolumn{5}{|l|}{ Sex } \\
\hline Male & $87(52.7)$ & $87(52.7)$ & $174(52.7)$ & 1.00 \\
\hline Female & $78(47.3)$ & $78(47.3)$ & $156(47.3)$ & \\
\hline \multicolumn{5}{|l|}{ Age groups (in years) } \\
\hline$\leq 40$ & $14(8.5)$ & $14(8.5)$ & $28(8.5)$ & 1.00 \\
\hline $41-50$ & $33(20.0)$ & $33(20.0)$ & $66(20.0)$ & \\
\hline $51-60$ & $72(43.6)$ & $72(43.6)$ & $144(43.6)$ & \\
\hline $61-70$ & $37(22.4)$ & $37(22.4)$ & $74(22.4)$ & \\
\hline$>70$ & $9(5.5)$ & $9(5.5)$ & $18(5.5)$ & \\
\hline \multicolumn{5}{|l|}{ Marital status } \\
\hline Married & $122(73.9)$ & $145(87.9)$ & $267(80.9)$ & 0.00 \\
\hline Single & $7(4.2)$ & $7(4.2)$ & $14(4.2)$ & \\
\hline Divorced/separated & $15(9.1)$ & $10(6.1)$ & $25(7.6)$ & \\
\hline Widowed & $21(12.7)$ & $3(1.8)$ & $24(7.3)$ & \\
\hline \multicolumn{5}{|l|}{ Educational level } \\
\hline Primary or less & $33(20.0)$ & $4(2.4)$ & $37(11.2)$ & 0.00 \\
\hline At least secondary & $132(80.0)$ & $161(97.6)$ & $293(88.8)$ & \\
\hline \multicolumn{5}{|l|}{ Religion } \\
\hline Pentecostal & $74(44.8)$ & $51(30.9)$ & $125(75.8)$ & 0.00 \\
\hline Orthodox & $22(13.3)$ & $28(17.0)$ & $50(15.2)$ & \\
\hline Catholic & $53(32.1)$ & $83(50.3)$ & $136(41.2)$ & \\
\hline Others & $16(9.8)$ & $3(1.8)$ & $19(5.8)$ & \\
\hline \multicolumn{5}{|l|}{ Smoking status } \\
\hline Yes (currently) & $6(3.6)$ & $0(0.0)$ & $6(1.8)$ & 0.00 \\
\hline Smoked previously but stopped & $57(34.5)$ & $28(17.0)$ & $85(25.8)$ & \\
\hline Never & $102(61.9)$ & $137(83.0)$ & $239(72.4)$ & \\
\hline \multicolumn{5}{|l|}{ Consume alcohol } \\
\hline Frequently & $12(7.3)$ & $7(4.2)$ & $19(5.8)$ & 0.00 \\
\hline Occasionally & $21(12.7)$ & $47(28.5)$ & $68(20.6)$ & \\
\hline Rarely & $67(40.6)$ & $60(36.4)$ & $127(38.5)$ & \\
\hline Never & $65(39.4)$ & $51(30.9)$ & $116(35.1)$ & \\
\hline \multicolumn{5}{|l|}{ BMI category } \\
\hline Normal & $41(24.9)$ & $87(52.7)$ & $128(38.8)$ & 0.00 \\
\hline Overweight & $85(51.5)$ & $75(45.5)$ & $160(48.5)$ & \\
\hline Obese & $39(23.6)$ & $3(1.8)$ & $42(12.7)$ & \\
\hline \multicolumn{5}{|l|}{ Comorbid hypertension } \\
\hline Yes & $141(85.5)$ & $0(0.0)$ & $141(42.7)$ & 0.00 \\
\hline No & $24(14.5)$ & $165(100)$ & $189(59.3)$ & \\
\hline
\end{tabular}

found among hypertensive compared with normotensive subjects, though this difference was not statistically significant $(p>0.05)$. However, systemic blood pressure was significantly and indirectly correlated with QoL for both sexes. Duration of diabetes and hypertension were indirectly correlated with QoL score but statistical significance was found only for males. Fasting blood sugar (FBS) level and lipid profile were not significantly correlated with QoL score in both sexes. 
Table 2 Comparison of QoL scores among female patients with diabetes and controls in Calabar $(N=156)$

\begin{tabular}{|c|c|c|c|}
\hline \multirow[t]{2}{*}{ Variable } & \multirow{2}{*}{$\begin{array}{l}\text { Case }(n=78) \\
\text { Mean } \pm \text { SD }\end{array}$} & \multirow{2}{*}{$\begin{array}{l}\text { Control }(n=78) \\
\text { Mean } \pm \text { SD }\end{array}$} & \multirow[t]{2}{*}{$p$ value } \\
\hline & & & \\
\hline \multicolumn{4}{|l|}{ General (non-domain) questions } \\
\hline 1 How would you rate your quality of life? & $3.64 \pm 0.87$ & $3.94 \pm 0.67$ & $0.02^{*}$ \\
\hline 2 How satisfied are you with your health? & $3.04 \pm 1.04$ & $3.72 \pm 0.68$ & $0.00^{*}$ \\
\hline \multicolumn{4}{|l|}{ Physical health domain } \\
\hline 3 How much physical pain prevents you from doing things? & $3.47 \pm 1.24$ & $3.68 \pm 0.80$ & 0.22 \\
\hline 4 How much do you need medical treatment to function daily? & $2.59 \pm 0.92$ & $3.85 \pm 1.03$ & $0.00^{*}$ \\
\hline 10 Do you have enough energy for everyday life? & $3.22 \pm 0.95$ & $3.62 \pm 0.87$ & $0.01^{*}$ \\
\hline 15 How well are you able to go around? & $3.35 \pm 0.74$ & $3.13 \pm 1.06$ & 0.14 \\
\hline 16 How satisfied are you with your sleep? & $2.95 \pm 1.01$ & $3.82 \pm 0.86$ & $0.00^{*}$ \\
\hline 17 How satisfied are you with ability to perform daily activities? & $3.36 \pm 1.02$ & $3.42 \pm 0.59$ & 0.63 \\
\hline 18 How satisfied are you with your capacity for work? & $3.29 \pm 0.87$ & $3.37 \pm 0.74$ & 0.55 \\
\hline Subtotal score for physical health & $22.23 \pm 5.04$ & $24.88 \pm 3.36$ & $0.00^{*}$ \\
\hline \multicolumn{4}{|l|}{ Psychological health domain } \\
\hline 5 How much do you enjoy life? & $2.49 \pm 1.14$ & $2.40 \pm 0.81$ & 0.57 \\
\hline 6 To what extent do you feel your life to be meaningful? & $2.35 \pm 0.82$ & $2.44 \pm 0.59$ & 0.44 \\
\hline 7 How well are you able to concentrate? & $2.82 \pm 1.02$ & $3.26 \pm 0.87$ & $0.01^{*}$ \\
\hline 11 Are you able to accept your bodily appearance? & $3.62 \pm 1.08$ & $4.12 \pm 0.82$ & $0.00^{*}$ \\
\hline 19 How satisfied are you with yourself? & $3.69 \pm 0.74$ & $3.96 \pm 0.89$ & $0.04^{*}$ \\
\hline $\begin{array}{l}26 \text { How often do you have negative feelings such as mood, despair, anxiety, } \\
\text { and depression? }\end{array}$ & $4.31 \pm 0.71$ & $3.21 \pm 0.92$ & $0.00^{*}$ \\
\hline Subtotal score for psychological health & $19.27 \pm 1.46$ & $19.37 \pm 1.76$ & 0.69 \\
\hline \multicolumn{4}{|l|}{ Social Relationship Domain } \\
\hline 20 How satisfied are you with your personal relationships? & $3.47 \pm 1.11$ & $3.79 \pm 0.95$ & 0.05 \\
\hline 21 How satisfied are you with the support you get from friends? & $2.78 \pm 1.27$ & $2.49 \pm 1.13$ & 0.13 \\
\hline 22 How satisfied are you with your sex life? & $3.21 \pm 1.11$ & $3.64 \pm 1.00$ & $0.01^{*}$ \\
\hline Subtotal score for social relationship & $9.46 \pm 2.62$ & $9.92 \pm 2.29$ & 0.24 \\
\hline \multicolumn{4}{|l|}{ Environment domain } \\
\hline 8 How safe do you feel in your daily life? & $3.22 \pm 0.75$ & $3.26 \pm 0.55$ & 0.72 \\
\hline 9 How healthy is your physical environment? & $3.28 \pm 0.70$ & $4.09 \pm 0.93$ & $0.00^{*}$ \\
\hline 12 Have you enough money to meet your needs? & $2.68 \pm 0.71$ & $3.05 \pm 0.82$ & $0.00^{*}$ \\
\hline 13 How available to you is the information that you need daily? & $2.72 \pm 0.88$ & $2.38 \pm 0.89$ & $0.02^{*}$ \\
\hline 14 To what extent do you have the opportunity for leisure? & $2.91 \pm 0.74$ & $2.00 \pm 1.02$ & $0.00^{*}$ \\
\hline 23 How satisfied are you with condition of your living space? & $2.86 \pm 0.99$ & $2.87 \pm 1.36$ & 0.95 \\
\hline 24 How satisfied are you with your access to health? & $3.14 \pm 0.96$ & $3.04 \pm 1.05$ & 0.53 \\
\hline 25 How satisfied are you with your transport? & $3.00 \pm 0.91$ & $2.96 \pm 0.97$ & $0.04^{*}$ \\
\hline Subtotal score for environment & $23.81 \pm 4.13$ & $23.65 \pm 4.50$ & 0.82 \\
\hline Domain-based total QoL score & $74.77 \pm 11.4$ & $77.83 \pm 10.1$ & 0.08 \\
\hline
\end{tabular}

*Significant $p$ value

\section{Discussion}

This study aimed at assessing health-related quality of life (HRQoL) among men and women with diabetes and comparing it with their controls in a tertiary health service in Nigeria. There was no significant difference in the overall quality of life between cases and controls in both sexes $(p>0.05)$. Diabetic women compared with controls had lower HRQoL score for physical health domain only, while diabetic men compared with controls had lower HRQoL for both physical health and social relationship domains. This implies that diabetes has significant impact on physical health for both sexes and 
Table 3 Comparison of QoL scores among male patients with diabetes and controls in Calabar $(N=174)$

\begin{tabular}{|c|c|c|c|}
\hline \multirow[t]{2}{*}{ Variable } & \multirow{2}{*}{$\begin{array}{l}\text { Case }(n=87) \\
\text { Mean } \pm \text { SD }\end{array}$} & \multirow{2}{*}{$\begin{array}{l}\text { Control }(n=87) \\
\text { Mean } \pm \text { SD }\end{array}$} & \multirow[t]{2}{*}{$p$ value } \\
\hline & & & \\
\hline \multicolumn{4}{|l|}{ General (non-domain) questions } \\
\hline 1 How would you rate your quality of life? & $3.79 \pm 0.89$ & $3.55 \pm 0.57$ & $0.03^{*}$ \\
\hline 2 How satisfied are you with your health? & $3.38 \pm 0.97$ & $3.52 \pm 0.86$ & 0.32 \\
\hline \multicolumn{4}{|l|}{ Physical health domain } \\
\hline 3 How much physical pain prevents you from doing things? & $4.17 \pm 0.99$ & $3.72 \pm 0.87$ & $0.00^{*}$ \\
\hline 4 How much do you need medical treatment to function daily? & $3.03 \pm 1.01$ & $4.24 \pm 0.78$ & $0.00^{*}$ \\
\hline 10 Do you have enough energy for everyday life? & $3.14 \pm 0.82$ & $3.38 \pm 0.85$ & 0.06 \\
\hline 15 How well are you able to go around? & $3.59 \pm 0.62$ & $3.10 \pm 0.76$ & $0.00^{*}$ \\
\hline 16 How satisfied are you with your sleep? & $2.97 \pm 1.07$ & $3.45 \pm 0.82$ & $0.00^{*}$ \\
\hline 17 How satisfied are you with ability to perform daily activities? & $3.00 \pm 1.09$ & $3.17 \pm 0.70$ & 0.22 \\
\hline 18 How satisfied are you with your capacity for work? & $3.17 \pm 0.96$ & $3.52 \pm 0.78$ & $0.01^{*}$ \\
\hline Subtotal score for physical health & $23.07 \pm 4.70$ & $24.59 \pm 3.57$ & $0.02^{*}$ \\
\hline \multicolumn{4}{|l|}{ Psychological health domain } \\
\hline 5 How much do you enjoy life? & $2.45 \pm 0.62$ & $2.55 \pm 0.68$ & 0.30 \\
\hline 6 To what extent do you feel your life to be meaningful? & $2.45 \pm 0.77$ & $2.69 \pm 0.70$ & $0.03^{*}$ \\
\hline 7 How well are you able to concentrate? & $3.17 \pm 0.88$ & $3.14 \pm 0.63$ & 0.77 \\
\hline 11 Are you able to accept your bodily appearance? & $3.34 \pm 1.03$ & $3.72 \pm 0.87$ & 0.10 \\
\hline 19 How satisfied are you with yourself? & $3.62 \pm 0.77$ & $3.55 \pm 0.97$ & 0.60 \\
\hline 26 How often do you have negative feelings such as mood, despair, anxiety, and depression? & $4.48 \pm 0.73$ & $3.76 \pm 0.82$ & $0.00^{*}$ \\
\hline Subtotal score for psychological health & $19.52 \pm 2.17$ & $19.41 \pm 1.95$ & 0.74 \\
\hline \multicolumn{4}{|l|}{ Social relationship domain } \\
\hline 20 How satisfied are you with your personal relationships? & $3.24 \pm 1.01$ & $3.76 \pm 0.78$ & $0.00^{*}$ \\
\hline 21 How satisfied are you with the support you get from friends? & $2.93 \pm 1.35$ & $3.14 \pm 1.05$ & 0.26 \\
\hline 22 How satisfied are you with your sex life? & $3.24 \pm 1.23$ & $3.30 \pm 1.42$ & 0.78 \\
\hline Subtotal score for social relationship & $9.41 \pm 2.74$ & $10.20 \pm 2.32$ & $0.04^{*}$ \\
\hline \multicolumn{4}{|l|}{ Environment domain } \\
\hline 8 How safe do you feel in your daily life? & $3.24 \pm 0.73$ & $3.41 \pm 0.62$ & 0.10 \\
\hline 9 How healthy is your physical environment? & $3.28 \pm 0.74$ & $3.76 \pm 0.90$ & $0.00^{*}$ \\
\hline 12 Have you enough money to meet your needs? & $3.00 \pm 0.84$ & $2.69 \pm 0.70$ & $0.01^{*}$ \\
\hline 13 How available to you is the information that you need daily? & $2.93 \pm 0.79$ & $2.14 \pm 0.94$ & $0.00^{*}$ \\
\hline 14 To what extent do you have the opportunity for leisure? & $2.72 \pm 0.87$ & $2.48 \pm 1.17$ & 0.13 \\
\hline 23 How satisfied are you with condition of your living space? & $3.10 \pm 0.81$ & $3.62 \pm 0.67$ & $0.00^{*}$ \\
\hline 24 How satisfied are you with your access to health? & $3.17 \pm 1.09$ & $2.07 \pm 1.24$ & $0.00^{*}$ \\
\hline 25 How satisfied are you with your transport? & $3.31 \pm 0.84$ & $3.07 \pm 0.64$ & $0.04^{*}$ \\
\hline Subtotal score for environment & $24.76 \pm 3.97$ & $23.24 \pm 3.58$ & $0.01^{*}$ \\
\hline Domain-based Total QoL score & $76.76 \pm 11.7$ & $77.44 \pm 9.53$ & 0.68 \\
\hline
\end{tabular}

*Significant $p$ value

additional impact on the social relationship among men in the study setting. Similar studies in Canada [23], Saudi Arabia [24], Israel [25], Spain [26], and Bangladesh [27] found significantly lower physical and mental health QoL scores among cases compared with controls $(p<$ $0.05)$. These findings are however not in line with a similar study in India [28], where there was no significant difference in overall HRQoL score and scores for each of the domains comparing diabetic and nondiabetic subjects. Differences in findings may be due to differences in ethnicity and sociocultural determinants of health and well-being in different settings, as well as potential difference in perception of health status and response to the different instruments used for 
Table 4 Relationship between characteristics and QoL among cases in Calabar ( $N=165$ )

\begin{tabular}{|c|c|c|c|c|c|c|}
\hline Sex & Variable & $\begin{array}{l}\text { Total } \\
\text { mean } \pm \text { SD }\end{array}$ & $\begin{array}{l}\text { Phys. Health } \\
\text { Mean } \pm \text { SD }\end{array}$ & $\begin{array}{l}\text { Psych. Health } \\
\text { mean } \pm \text { SD }\end{array}$ & $\begin{array}{l}\text { Soc. Rel. } \\
\text { mean } \pm \text { SD }\end{array}$ & $\begin{array}{l}\text { Environment } \\
\text { mean } \pm S D\end{array}$ \\
\hline \multirow[t]{18}{*}{ Females $(n=78)$} & Age group (in years) & & & & & \\
\hline & $\leq 50$ & $78.86 \pm 12.26$ & $24.33 \pm 5.34$ & $19.17 \pm 1.44$ & $9.76 \pm 2.77$ & $25.10 \pm 3.90$ \\
\hline & $>50$ & $72.35 \pm 10.17$ & $20.69 \pm 4.20$ & $19.33 \pm 1.48$ & $9.29 \pm 2.53$ & $23.04 \pm 4.11$ \\
\hline & $t$ test $p$ value & $0.01^{*}$ & $0.00^{*}$ & 0.66 & 0.44 & $0.03^{*}$ \\
\hline & Marital status & & & & & \\
\hline & Married & $76.85 \pm 11.67$ & $22.72 \pm 5.29$ & $19.47 \pm 1.64$ & $10.19 \pm 2.67$ & $24.47 \pm 3.91$ \\
\hline & Unmarried & $70.36 \pm 9.46$ & $21.20 \pm 4.39$ & $18.84 \pm 0.85$ & $7.92 \pm 1.71$ & $22.40 \pm 4.31$ \\
\hline & $p$ value & $0.02^{*}$ & 0.22 & 0.07 & $0.00^{*}$ & $0.04^{*}$ \\
\hline & Educational level & & & & & \\
\hline & Primary or none & $73.76 \pm 9.46$ & $21.33 \pm 4.58$ & $19.52 \pm 1.47$ & $9.38 \pm 1.77$ & $23.52 \pm 2.91$ \\
\hline & At least secondary & $75.14 \pm 12.05$ & $22.56 \pm 5.20$ & $19.18 \pm 1.45$ & $9.49 \pm 2.88$ & $23.91 \pm 4.52$ \\
\hline & $p$ value & 0.64 & 0.34 & 0.35 & 0.87 & 0.72 \\
\hline & Religion & & & & & \\
\hline & Pentecostal & $76.69 \pm 13.99$ & $23.88 \pm 5.68$ & $19.81 \pm 1.30$ & $9.77 \pm 3.02$ & $23.23 \pm 4.95$ \\
\hline & Orthodox & $71.60 \pm 7.37$ & $19.30 \pm 2.87$ & $19.20 \pm 1.03$ & $8.30 \pm 2.36$ & $24.80 \pm 4.37$ \\
\hline & Catholic & $71.97 \pm 9.69$ & $20.71 \pm 4.23$ & $18.51 \pm 1.25$ & $9.54 \pm 2.61$ & $23.20 \pm 3.42$ \\
\hline & Others & $73.42 \pm 11.07$ & $21.30 \pm 3.07$ & $19.17 \pm 1.07$ & $9.57 \pm 0.54$ & $23.74 \pm 3.54$ \\
\hline & $p$ value & 0.12 & 0.09 & 0.14 & 0.51 & 0.67 \\
\hline \multirow[t]{18}{*}{ Males $(n=87)$} & Age group (in years) & & & & & \\
\hline & $\leq 50$ & $82.50 \pm 10.80$ & $24.83 \pm 4.88$ & $20.33 \pm 2.28$ & $10.17 \pm 2.01$ & $27.17 \pm 3.00$ \\
\hline & $>50$ & $75.26 \pm 11.50$ & $22.61 \pm 4.63$ & $19.30 \pm 2.11$ & $9.22 \pm 2.88$ & $24.13 \pm 3.97$ \\
\hline & $t$ test ( $p$ value) & $0.02^{*}$ & 0.08 & 0.07 & 0.19 & $0.00^{*}$ \\
\hline & Marital status & & & & & \\
\hline & Married & $76.70 \pm 11.24$ & $23.35 \pm 4.29$ & $19.39 \pm 2.26$ & $9.22 \pm 2.79$ & $24.74 \pm 4.05$ \\
\hline & Unmarried & $77.00 \pm 13.60$ & $22.00 \pm 6.20$ & $20.00 \pm 1.78$ & $10.17 \pm 2.48$ & $24.83 \pm 3.73$ \\
\hline & $t$ test ( $p$ value) & 0.92 & 0.29 & 0.29 & 0.19 & 0.93 \\
\hline & Educational level & & & & & \\
\hline & Primary or none & $75.25 \pm 8.34$ & $21.50 \pm 5.25$ & $19.75 \pm 0.45$ & $10.25 \pm 3.57$ & $23.75 \pm 2.38$ \\
\hline & At least secondary & $77.00 \pm 12.15$ & $23.32 \pm 4.64$ & $19.48 \pm 2.33$ & $9.28 \pm 2.59$ & $24.92 \pm 4.16$ \\
\hline & $t$ test ( $p$ value) & 0.63 & 0.22 & 0.69 & 0.26 & 0.35 \\
\hline & Religion & & & & & \\
\hline & Pentecostal & $75.38 \pm 12.56$ & $22.81 \pm 4.86$ & $19.06 \pm 2.61$ & $8.94 \pm 2.69$ & $24.56 \pm 4.30$ \\
\hline & Orthodox & $71.75 \pm 8.94$ & $20.00 \pm 3.91$ & $18.75 \pm 1.14$ & $10.75 \pm 3.17$ & $22.25 \pm 2.38$ \\
\hline & Catholic & $78.67 \pm 9.87$ & $23.83 \pm 4.50$ & $20.33 \pm 0.49$ & $8.50 \pm 2.20$ & $26.00 \pm 3.61$ \\
\hline & Others & $73.49 \pm 10.07$ & $21.62 \pm 2.29$ & $19.10 \pm 1.07$ & $9.17 \pm 1.61$ & $23.44 \pm 2.91$ \\
\hline & $p$ value & 0.09 & 0.19 & 0.11 & 0.21 & 0.08 \\
\hline
\end{tabular}

*Significant $p$ value

assessment of HRQoL [26, 29]. Physical health effects may result from complications which progressively debilitate and prevent effective performance of daily activities. Also, potential presence of adverse sexual dysfunction, as well as adherence to nutritional and other lifestyle restrictions required for better diabetes care, may be the reasons behind the higher impact on the social relationship in men with diabetes than women in the study setting [11].

In this study, the QoL score for the environment domain was higher among cases compared with controls, but with statistical significance only among men. This finding may be because cases due to their disease condition may be having better access to locally available 
Table 5 Relationship between clinical parameters and QoL score among cases in Calabar, Nigeria $(N=165)$

\begin{tabular}{|c|c|c|}
\hline Variable & $\begin{array}{l}\text { Female QoL } \\
\text { score mean } \pm \text { SD } \\
(n=78)\end{array}$ & $\begin{array}{l}\text { Male QoL score } \\
\text { mean } \pm \text { SD } \\
(n=87)\end{array}$ \\
\hline \multicolumn{3}{|l|}{ Comorbid hypertension } \\
\hline Yes & $73.9 \pm 11.2$ & $76.00 \pm 13.6$ \\
\hline No & $78.6 \pm 11.6$ & $76.85 \pm 11.5$ \\
\hline$p$ value & 0.15 & 0.84 \\
\hline \multicolumn{3}{|l|}{ BMI } \\
\hline Normal & $77.3 \pm 10.2$ & $76.5 \pm 11.1$ \\
\hline Overweight or obese & $71.6 \pm 10.8$ & $70.1 \pm 9.62$ \\
\hline$p$ value & $0.03^{*}$ & $0.02^{*}$ \\
\hline \multicolumn{3}{|l|}{ HbA1c status } \\
\hline Good control (< 7.0\%) & $75.1 \pm 9.3$ & $76.6 \pm 9.8$ \\
\hline Poor control ( $\geq 7.0 \%)$ & $66.7 \pm 9.6$ & $68.2 \pm 9.1$ \\
\hline$p$ value & $0.00^{*}$ & $0.00^{*}$ \\
\hline \multicolumn{3}{|l|}{ Duration of diabetes } \\
\hline Correlation coef. ( $p$ value) & $-0.06(0.58)$ & $-0.32(0.00)^{*}$ \\
\hline \multicolumn{3}{|l|}{ Duration of hypertension } \\
\hline Correlation coef. ( $p$ value) & $-0.06(0.64)$ & $-0.29(0.01) *$ \\
\hline \multicolumn{3}{|l|}{ Systolic blood pressure } \\
\hline Correlation coef. ( $p$ value) & $-0.22(0.05)$ & $-0.21(0.05)$ \\
\hline \multicolumn{3}{|l|}{ Diastolic blood pressure } \\
\hline Correlation coef. ( $p$ value) & $-0.24(0.03) *$ & $-0.24(0.03) *$ \\
\hline \multicolumn{3}{|l|}{ Mean blood pressure } \\
\hline Correlation coef. ( $p$ value) & $-0.24(0.03) *$ & $-0.18(0.09)$ \\
\hline \multicolumn{3}{|l|}{ Fasting blood sugar } \\
\hline Correlation coef. ( $p$ value) & $0.17(0.14)$ & $0.19(0.11)$ \\
\hline \multicolumn{3}{|l|}{ Total cholesterol } \\
\hline Correlation coef. ( $p$ value) & $-0.02(0.85)$ & $-0.07(0.73)$ \\
\hline \multicolumn{3}{|l|}{ HDL cholesterol } \\
\hline Correlation coef. ( $p$ value) & $0.13(0.25)$ & $-0.29(0.79)$ \\
\hline \multicolumn{3}{|l|}{ LDL cholesterol } \\
\hline Correlation coef. ( $p$ value) & $0.17(0.14)$ & $-0.19(0.11)$ \\
\hline \multicolumn{3}{|l|}{ Triglycerides } \\
\hline Correlation coef. ( $p$ value) & $-0.24(0.03) *$ & $-0.21(0.05)$ \\
\hline
\end{tabular}

*Significant $p$ value

healthcare services, health information, and awareness of the need and means of relaxation and leisure for better well-being, compared with controls [30, 31]. This may also be a reflection of poor knowledge and non-practice of healthy living, including poor attitude to health seeking at least for regular medical check-up among apparently healthy individuals in the general population [32].

Increasing age was associated with lower QoL among cases, with statistical significance for environment domain for both sexes and physical domain for females only. With increasing age, the functional capacity may be significantly impaired, especially among individuals who had previously lived sedentary lifestyle $[33,34]$. This impairment may contribute to low HRQoL especially among older people with chronic diseases. Unlike the more developed settings, older people in the less developed study setting do not have improved access to healthcare, housing, security, and recreation, and therefore have lower QoL score in the environment domain. This may be a reflection of poor means of transportation, worsening insecurity, poor retirement benefit, and lack of health insurance and requisite infrastructure for healthful living of older people in developing countries [35]. This suggest that general economic and infrastructural development through good and consistent political will of government play key roles in determining the overall quality of life of patients with diabetes in developing countries.

Unlike males, unmarried females with diabetes had significantly lower QoL than married female cases. A similar study in Greece [36] found unmarried status to be a significant predictor of lower HRQoL among patients with diabetes of both sexes. This suggests that in the study setting, marital status may be key determinant of QoL among diabetic women, perhaps via the socioculturally driven potential stigma and perception of unfulfilled life among older females who are unmarried [37]. Counseling during clinic sessions including active involvement in family and suitable social support groups and consistent media-based societal reorientation may be useful for cushioning this effect of unmarried status on HRQoL among women with diabetes in developing countries [35].

The presence of comorbid hypertension was not significantly associated with HRQoL for both sexes in this study. This is in contrast with reports from studies in Greece [36], and Spain [38], where presence of hypertension and other comorbidities was associated with lower HRQoL scores. However, in this study, subjects' systemic blood pressures were found to be indirectly correlated with HRQoL. This finding suggests that blood pressure control rather than presence of hypertension was key to maintaining or improving HRQoL among patients with diabetes in the study setting. Uncontrolled blood pressure increases cost of care, as well as risk of anxiety, depression, and multiple end-organ complications which ultimately impair QoL $[39,40]$. Also, laboratory measurements including FBS and HbA1c were not associated with HRQoL in this study. This is not in agreement with the result of a similar study in Saudi Arabia [24], where patients with uncontrolled/poorly controlled blood sugar levels were found to have significantly lower HRQoL scores compared with controlled patients. Patients with diabetes in this study setting may be less aware or be nonchalant about the potential health 
implications of poor blood sugar control. Despite awareness of risk of complications, as long as there are no current symptoms of the disease or medication sideeffects, patients may continue with unhealthy habits such as excessive alcohol consumption, perhaps due to false perception of good QoL [41]. More superior prospective study designs will be required for better understanding of the factors and relationship between glycemic control and HRQoL in the study setting.

This study is one of the few researches utilizing a control study group to assess impact of diabetes on QoL in sub-Saharan Africa, where the chronic disease is rapidly rising. The findings provide useful data for endocrinologist, clinical psychologist, social workers, and other members of multidisciplinary teams involved in optimum diabetes care. The study also reveals common and genderbased differences in the effect of sociodemographic, clinical, and laboratory factors on QoL among patients with diabetes in a developing country setting. For instance, older age and poorly controlled systemic blood pressure are factors that commonly impaired the QoL for both sexes. However, while the effect of marital status mainly applied to females, the duration of comorbid hypertension mainly applied to males. These findings may be useful for improvement of the quality of counseling, as well as updating existing policies and guidelines for improvement in best practice of diabetes care in developing countries [42].

\subsection{Study limitations}

A key limitation of this study was the assessment of hypertension as the only common comorbid disease among diabetic cases. Presence of comorbidities among diabetic cases may have contributed to overestimation of impairment in HRQoL attributable to diabetes. Therefore, assessment of comorbid presence of other chronic diseases (such as cancer, COPD, arthritis, peptic ulcer, and HIV) may have been useful for better understanding of the dynamics of QoL among patients with diabetes in the study setting [43]. Also, inference of causality between identified factors of QoL among patients with diabetes will require more extensive studies with superior study design. This may include experimental design which will assess QoL effects of intervening on identified factors, as well as longitudinal studies in view of potential changes of HRQoL with time in the same individuals [44].

\section{Conclusion}

There is suboptimal QoL among male and female patients with diabetes. There was no significant difference in the overall QoL between diabetics and controls. However, the physical domain (for both sexes) and social domain (for males only) were significantly impaired among patients with diabetes compared with the controls. Poor control of blood pressure rather than comorbid presence of hypertension further worsens QoL among diabetics. Also, there were common as well as gender-based differences in factors associated with QoL among patients with diabetes, with implications for improvement in best diabetes care in developing countries. Healthcare workers' adherence to best practice guidelines for diabetes care and improvement in healthcare access may significantly improve physical health and social relationship QoL of patients with diabetes in the study setting. Further research on QoL among diabetics should be conducted with inclusion of key chronic diseases and social support, which potentially affects QoL. Qualitative research is also recommended for better understanding of the role of psychosocial factors and coping strategies on the QoL among patients with diabetes.

\section{Abbreviations}

ANOVA: Analysis of variance; BMl: Body mass index; COPD: Chronic obstructive pulmonary disease; FBS: Fasting blood sugar; HDL-C: High density lipoprotein cholesterol; HIV: Human immunodeficiency virus; HRQoL: Healthrelated quality of life; LDL-c: Low density lipoprotein cholesterol; NCD: Noncommunicable disease; QoL: Quality of life; SDGs: Sustainable development goals; UCTH: University of Calabar Teaching Hospital; WHOQoL: World Health Organization Quality of Life

\section{Acknowledgements \\ Not applicable \\ Ethics approval and consent to participate \\ The University of Calabar Teaching Hospital Health Research Ethics \\ Committee gave approval for the study (HREC/33/665: 12 March 2019). The study was also approved and supported by the Head of Department of Internal Medicine and Family Medicine, UCTH. All participants gave their informed and written consent before voluntary, anonymous, and confidential data collection.}

\section{Authors' contributions}

All authors contributed substantially to this work. Conceptualization and proposal writing was done by OE and OO. UA and AA supervised data collection. KN and AL managed the data and wrote the initial manuscript. $\mathrm{OE}$ and $\mathrm{OO}$ provided first revision while UA and AA did second revision of the manuscript. All authors have read and approved the manuscript.

\section{Funding}

This work was not supported financially.

\section{Availability of data and materials}

The corresponding author will make available data in this study upon request.

Consent for publication

Not applicable

\section{Competing interests}

The authors declare that there is no competing interest.

\section{Author details}

${ }^{1}$ Department of Internal Medicine, University of Calabar, Calabar, Nigeria.

${ }^{2}$ Department of Community Medicine, University of Calabar, Calabar, Nigeria.

${ }^{3}$ Department of Family Medicine, University of Calabar, Calabar, Nigeria. 
Received: 20 April 2020 Accepted: 4 November 2020 Published online: 28 January 2021

\section{References}

1. Bircher J, Kuruvilla S. Defining health by addressing individual, social, and environmental determinants: new opportunities for health care and public health. Journal of public health policy. 2014;35(3):363-86.

2. Costanza R, Daly L, Fioramonti L, Giovannini E, Kubiszewski I, Mortensen L, et al. Modelling and measuring sustainable wellbeing in connection with the UN Sustainable Development Goals. Ecological Economics. 2016;130(23): 350-5.

3. Nugent R, Bertram M, Jan S, Niessen L, Sassi F, Jamison D, et al. Investing in non-communicable disease prevention and management to advance the Sustainable Development Goals. Lancet. 2018;391(10134):2029-35.

4. Karimi M, Brazier J. Health, health-related quality of life, and quality of life: what is the difference? Pharmacoeconomics. 2016;34(7):645-9.

5. Boyle J, Thompson T, Gregg E, Barker L, Williamson D. Projection of the year 2050 burden of diabetes in the US adult population: dynamic modeling of incidence, mortality, and prediabetes prevalence. Population Health Metrics. 2010:8(1):29-34

6. Idemyor $V$. Diabetes in sub-Saharan Africa: health care perspectives, challenges, and the economic burden of disease. Journal of the National Medical Association. 2010;102(7):650-3.

7. Cho N, Shaw J, Karuranga S, Huang Y, da-Rocha-Fernandes J, Ohlrogge A, et al. IDF Diabetes Atlas: Global estimates of diabetes prevalence for 2017 and projections for 2045. Diabetes Res Clin Pract. 2018;138(12):271-81.

8. Ismail-Beigi F, Moghissi E, Tiktin M, Hirsch I, Inzucchi S, Genuth S. Individualizing glycemic targets in type 2 diabetes mellitus: implications of recent clinical trials. Annals of Internal Medicine. 2011;154(8):554-9.

9. Jing $X$, Chen J, Dong $Y$, Han D, Zhao H, Wang $X$, et al. Related factors of quality of life of type 2 diabetes patients: a systematic review and metaanalysis. Health and Quality of Life Outcomes. 2018 Dec 1;16(1):189.

10. Chinenye $\mathrm{S}$, Uloko AE, Ogbera AO, Ofoegbu EN, Fasanmade OA, Fasanmade $A A$, et al. Profile of Nigerians with diabetes mellitus-Diabcare Nigeria study group (2008): results of a multicenter study. Indian Journal of Endocrinology and Metabolism. 2012 Jul;16(4):558

11. Frandsen K, Kristensen J. Diet and lifestyle in type 2 diabetes: the patient's perspective. Practical Diabetes International. 2002;19(3):77-80.

12. Hall V, Thomsen R, Henriksen O, Lohse N. Diabetes in Sub Saharan Africa 1999-2011: epidemiology and public health implications: a systematic review. BMC Public Health. 2011;11(1):564-71.

13. Osei-Yeboah J, Owiredu WK, Norgbe GK, Lokpo SY, Allotey EA, Doe EA, et al. Quality of life of people living with type 2 diabetes in Ho, Ghana: a crosssectional study. Am J Biomedical Sci. 2016:8:4.

14. Gebremedhin T, Workicho A, Angaw DA. Health-related quality of life and its associated factors among adult patients with type II diabetes attending Mizan Tepi University Teaching Hospital, Southwest Ethiopia. BMJ Open Diabetes Research and Care. 2019;7:1

15. Akena D, Kadama P, Ashaba S, Akello C, Kwesiga B, Rejani L, et al. The association between depression, quality of life, and the health care expenditure of patients with diabetes mellitus in Uganda. Journal of Affective Disorders. 2015 Mar 15;174:7-12.

16. Werfalli M, Kassanjee R, Kalula S, Kowal P, Phaswana-Mafuya N, Levitt NS. Diabetes in South African older adults: prevalence and impact on quality of life and functional disability-as assessed using SAGE wave 1 data. Global Health Actions. 2018 Jan 1;11(1):1449924.

17. Lemeshow S, Hosmer DW, Klar J, Lwanga SK, World Health Organization. Adequacy of sample size in health studies. Chichester: Wiley; 1990

18. Akinyemi OO, Owoaje ET, Popoola OA, llesanmi OS. Quality of life and associated factors among adults in a community in South West Nigeria. Annals of Ibadan Postgraduate Medicine. 2012;10(2):34-9.

19. World Health Organization. The World Health Organization Quality of Life (WHOQOL). 2013.

20. World Health Organization. sWHOQOL-BREF: introduction, administration, scoring and generic version of the assessment: field trial version, December 1996. Geneva: World Health Organization; 1996.

21. Skevington SM, Lotfy M. O'Connell K2. The World Health Organization's WHOQOL-BREF quality of life assessment: psychometric properties and results of the international field trial. A report from the WHOQOL group. Qual Life Res. 2004 Mar 1;13(2):299-310.
22. American Diabetes Association. Glycemic targets: standards of medical care in diabetes - 2019. Diabetes Care. 2019;42(Supplement 1):S61-70.

23. Thommasen HV, Berkowitz J, Thommasen AT, Michalos AC. Understanding relationships between diabetes mellitus and health-related quality of life in a rural community. Rural Remote Health. 2005;5(3):441-7.

24. Al-Shehri AH, Taha AZ, Bahnassy AA, Salah M. Health-related quality of life in type 2 diabetic patients. Ann Saudi Med. 2008 Sep-Oct;28(5):352-60.

25. Eljedi A, Mikolajczyk RT, Kraemer A, Laaser U. Health-related quality of life in diabetic patients and controls without diabetes in refugee camps in the Gaza strip: a cross-sectional study. BMC Public Health. 2006;6(9):268-74.

26. Esteban MM, Hernandez-Barrera V, Fernandez-Cordero X, Gil-de-Miguel A, Rodriguez-Perez M, Lopez-de-Andres A, et al. Self-perception of health status, mental health and quality of life among adults with diabetes residing in a metropolitan area. Diabetes Metab. 2010;36(4):305-11.

27. Safita N, Islam SM, Chow CK, Niessen L, Lechner A, Holle R, et al. The impact of type 2 diabetes on health related quality of life in Bangladesh: results from a matched study comparing treated cases with non-diabetic controls. Health Qual Life Outcomes. 2016;14(1):129-34

28. Jain V, Shivkumar S, Gupta O. Health-related quality of life (hr-qol) in patients with type 2 diabetes mellitus. N Am J Med Sci. 2014;6(2):96-101.

29. Bagheri Z, Jafari $P$, Mahmoodi M, Dabbaghmanesh $M H$. Testing whether patients with diabetes and healthy people perceive the meaning of the items in the Persian version of the SF-36 questionnaire similarly: a differential item functioning analysis. Qual Life Res. 2017 Apr;26(4):835-45.

30. Cho J, Kim H, Han J, Lee J, Oh J, Choi Y, et al. Ubiquitous diabetes management system via interactive communication based on information technologies: clinical effects and perspectives. Korean Diabetes Journal. 2010;34(5):267-73

31. Odutola A. Developing countries must invest in access to information for health improvements. Journal of Medical Internet Research. 2003;5(1):5-10.

32. Bambra C, Gibson M, Sowden A, Wright K, Whitehead M, Petticrew M. Tackling the wider social determinants of health and health inequalities: evidence from systematic reviews. Journal of Epidemiology \& Community Health. 2010;64(4):284-91.

33. Awotidebe TO, Adedoyin RA, Oke Kl, Ativie RN, Opiyo R, Ikujeyisi EO, et al. Relationship between functional capacity and health-related quality of life of patients with type-2 diabetes. Diabetes Metab Syndr. 2017;11(1):1-5.

34. Baptista LC, Dias G, Souza NR, Verissimo MT, Martins RA. Effects of long-term multicomponent exercise on health-related quality of life in older adults with type 2 diabetes: evidence from a cohort study. Qual Life Res. 2017 Aug;26(8):2117-27.

35. Aboderin I. Understanding and advancing the health of older populations in sub-Saharan Africa: policy perspectives and evidence needs. Public Health Reviews. 2010;32(2):357-62.

36. Papadopoulos AA, Kontodimopoulos N, Frydas A, Ikonomakis E, Niakas D. Predictors of health-related quality of life in type $\|$ diabetic patients in Greece. BMC Public Health. 2007 Jul 30;7(13):186-92.

37. Chinenye S, Ogbera A. Socio-cultural aspects of diabetes mellitus in Nigeria. Journal of Social Health and Diabetes. 2013;1(11):15-21.

38. Pena-Longobardo LM, Rodriguez-Sanchez B, Mata-Cases M, RodriguezManas L, Capel M, Oliva-Moreno J. Is quality of life different between diabetic and non-diabetic people? The importance of cardiovascular risks. PLoS One. 2017;12(12):e0189505.

39. Wallace K, Zhao X, Misra R, Sambamoorthi U. The humanistic and economic burden associated with anxiety and depression among adults with comorbid diabetes and hypertension. J Diabetes Res. 2018;2018(21): 4842520.

40. Adeloye D, Ige J, Aderemi A, Adeleye N, Amoo E, Auta A, et al. Estimating the prevalence, hospitalisation and mortality from type 2 diabetes mellitus in Nigeria: a systematic review and meta-analysis. BMJ open. 2017;7(5):154-62

41. Chen ZC, Zhang SL, Yan L, Wu MC, Chen LH, Ji LN. Association between side effects of oral anti-diabetic drugs and self-reported mental health and quality of life among patients with type 2 diabetes. Zhonghua Yi Xue Za Zhi. 2011 Jan 25;91(4):229-33. (Chinese).

42. Widyahening I, Wangge $G$. van-der-Graaf $Y$, van-der-Heijden G. Adapting clinical guidelines in low-resources countries: a study on the guideline on the management and prevention of type 2 diabetes mellitus in Indonesia. Journal of Evaluation in Clinical Practice. 2017;23(1):121-7.

43. Ambriz-Murillo Y, Menor-Almagro R, Campos-Gonzalez ID, Cardiel MH. Health related quality of life in rheumatoid arthritis, osteoarthritis, diabetes 
mellitus, end stage renal disease and geriatric subjects. Experience from a General Hospital in Mexico. Reumatol Clin. 2015 Mar-Apr;1 1(2):68-72.

44. Schunk M, Reitmeir P, Ruckert-Eheberg IM, Tamayo T, Schipf S, Meisinger C, et al. Longitudinal change in health-related quality of life in people with prevalent and incident type 2 diabetes compared to diabetes-free controls. PLoS One. 2017;12(5):e0176895.

\section{Publisher's Note}

Springer Nature remains neutral with regard to jurisdictional claims in published maps and institutional affiliations.

Submit your manuscript to a SpringerOpen ${ }^{\circ}$ journal and benefit from:

- Convenient online submission

- Rigorous peer review

- Open access: articles freely available online

- High visibility within the field

- Retaining the copyright to your article

Submit your next manuscript at $\boldsymbol{\wedge}$ springeropen.com 